\title{
H2 Fuel Prototype Hydride Bed Performance Tests (U)
}

by

E: F. Dyer

Westinghouse Savannah River Company

Savannah River Site

Aiken, South Carolina 29808

DOE Contract No. DE-AC09-89SR18035

This paper was prepared in connection with work done under the above contract number with the U.S. Department of Energy. By acceptance of this paper, the publisher and/or recipient acknowledges the U.S. Government's right to retain a nonexclusive, royalty-free license in and to any copyright covering this paper, along with the right to reproduce and to authorize others to reproduce all or part of the copyrighted paper.

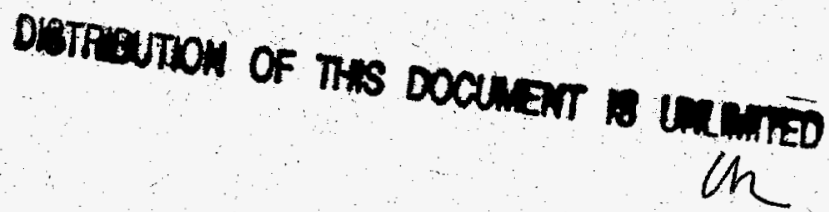




\section{DISCLAIMER}

This report was prepared as an account of work sponsored by an agency of the United States Government. Neither the United States Government nor any agency thereof, nor any of their employees, makes any warranty, express or implied, or assumes any legal liability or responsibility for the accuracy, completeness, or usefulness of any information, apparatus, product, or process disclosed, or represents that its use would not infringe privately owned rights. Reference herein to any specific commercial product, process, or service by trade name, trademark, manufacturer, or otherwise does not necessarily constitute or imply its endorsement, recommendation, or favoring by the United States Government or any agency thereof. The views and opinions of authors expressed herein do not necessarily state or reflect those of the United States Government or any agency thereof.

This report has been reproduced directly from the best available copy.

Available to DOE and DOE contractors from the Office of Scientific and Technical Information, P.O. Box 62, Oak Ridge, TN 37831; prices available from (615) 576-8401.

Available to the public from the National Technical Information Service, U.S. Department of Commerce; 5285 Port Royal Road, Springfield, VA 22161. 


\section{DISCLAIMER}

Portions of this document may be illegible in electronic image products. Images are produced from the best available original document. 
WSRC-TR-96-0342

\section{H2Fuel Prototype Hydride Bed Performance Tests (U)}

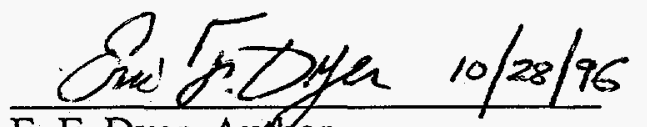

E. F. Dyer, Author

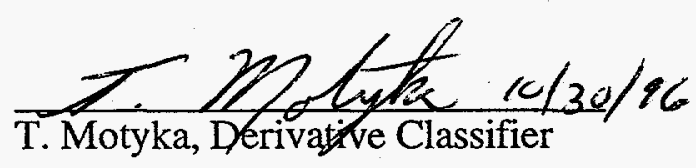

Z.K. Heung $10 / 30 / 96$

L. K. Heung, Technical Reviewer

Publication Date: October 1996

Westinghouse Savannah River Company Savannah River Site

Aiken, SC 29808

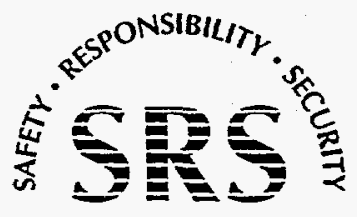

SAVANNAH RIVER SITE

Prepared for the U. S. Dept. of Energy under Contract No. DE-AC09-89SR18035 
This page intentionally left blank. 


\begin{abstract}
H2Fuel is a project to design, build, and demonstrate a hydrogen-electric hybrid city bus for Augusta, GA. The H2Fuel bus uses metal hydride technology for on-board hydrogen fuel storage. This document reports on tests by the Savannah River Technology Center (SRTC) to measure the performance of the H2Fuel prototype hydride bed. Bed diameter measurements were made before and after hydrogen testing. Seven hydrogen absorptiondesorption cycles were completed. Significant results include:

- maximum hydrogen capacity of approximately 3500 STP liters $(0.315 \mathrm{~kg})$

- practical hydrogen capacity of approximately 3000 STP liters $(0.270 \mathrm{~kg})$

- absorption tests at four hydrogen supply pressures $(75,100,140$, and 300 psia)

- desorption tests at three hydrogen rates $(20,30$, and $50 \mathrm{slpm})$

- no measurable swelling of the hydride bed
\end{abstract}


WSRC-TR-96-0342

This page intentionally left blank. 


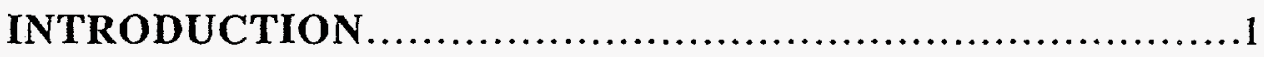

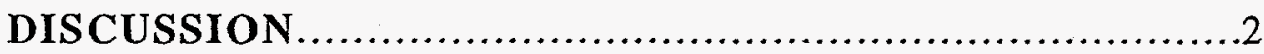

Hydride Beds.........................................................

Hydride Materials.................................................

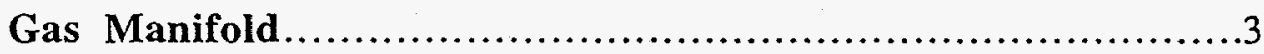

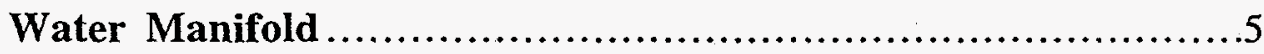

Data Acquisition System ........................................

Absorption Tests.......................................................

Desorption Tests ................................................ 10

Diameter Measurements..................................... 12

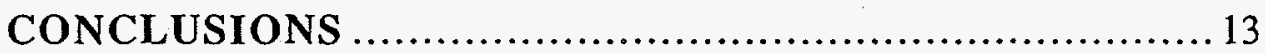

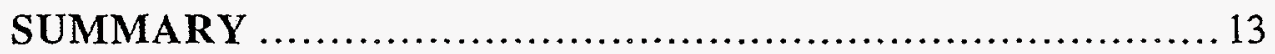




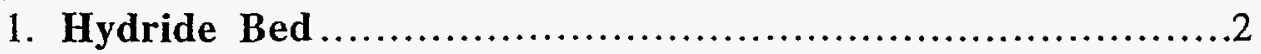

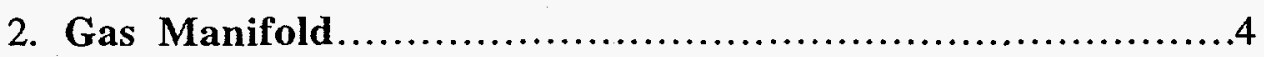

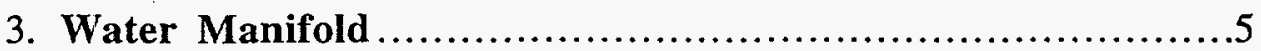

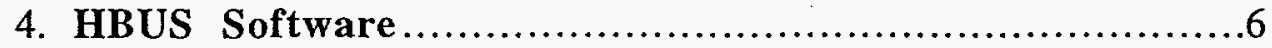

5. Absorption Results............................................ 8

6. Equilibrium Absorption Plateau Pressures......................9

7. Desorption Results ........................................... 11

\section{LIST OF TABLES}

1. Absorption Conditions...................................... 8

2. Charge Pressure Ratios.......................................

3. Desorption Conditions ........................................ 11

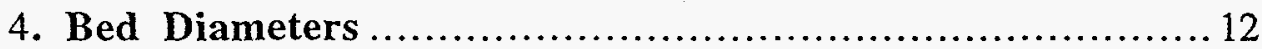




\section{INTRODUCTION}

H2Fuel is a project to design, build, and demonstrate a hydrogen-electric hybrid city bus for Augusta, GA. This bus will burn hydrogen in an internal combustion engine to turn an electric generator which will charge an array of batteries. The batteries will power an electric motor which will propel the bus. Hydrogen will be stored on board the bus as a metal hydride. The Savannah River Technology Center (SRTC) is responsible for design and procurement of the hydride based hydrogen storage system for the H2Fuel bus.

In January 1996 a prototype hydride bed was built by Hydrogen Consultants, Inc. (HCI). HCI completed a series of tests (seven hydrogen absorption-desorption cycles) to measure the performance of this prototype bed in February 1996. The results of tests by HCI showed that the hydride vessel performed well, but that the desorption pressure of the hydride needed to be increased by a factor of two to three times to satisfy the pressure demands of the internal combustion engine. The composition of the final bus hydride was changed to accomplish the needed increase in desorption pressure. This report describes additional testing of the H2Fuel prototype hydride bed by SRTC to confirm and extend the results obtained by $\mathrm{HCI}$. 


\section{DISCUSSION}

\section{Hydride Beds}

Figure 1 is a schematic diagram of the H2Fuel prototype hydride bed. The bed container consists of a 60 " long, 3.5" diameter stainless steel tube divided into twelve sections by aluminum plates. Each section contains aluminum foam to increase the thermal conductivity of the bed. Metal hydride powder occupies much of the aluminum foam void space. The divider plates help ensure a uniform distribution of hydride along the length of the bed. Water is circulated through an internal U-shaped tube to heat and cool the bed. An internal porous metal tube is used to filter the gas that flows in and out of the bed. The bed has a maximum allowable working pressure of 500 psig and weighs approximately $35.9 \mathrm{~kg}$ (10.1 kg vessel + $25.8 \mathrm{~kg}$ hydride).

The final H2Fuel hydrogen storage system includes two groups of twenty-four hydride beds which supply hydrogen to an internal combustion engine. The approximate hydrogen requirements to operate the engine at full speed are a pressure of $6 \mathrm{~atm}$. and a flow rate of $1200 \mathrm{slpm}$. Normal cooling water (about $25 \mathrm{degC}$ ) is used to cool the beds during hydrogen absorption. Warm engine coolant is used to heat the beds to desorb hydrogen. If both groups of beds are desorbed in parallel then each bed must supply approximately 25 slpm of hydrogen. If the two groups of beds are desorbed in series then each bed must deliver approximately $50 \mathrm{slpm}$ of hydrogen. The final hydride beds are nearly identical to the prototype bed except for a small change in the composition of the hydride material.

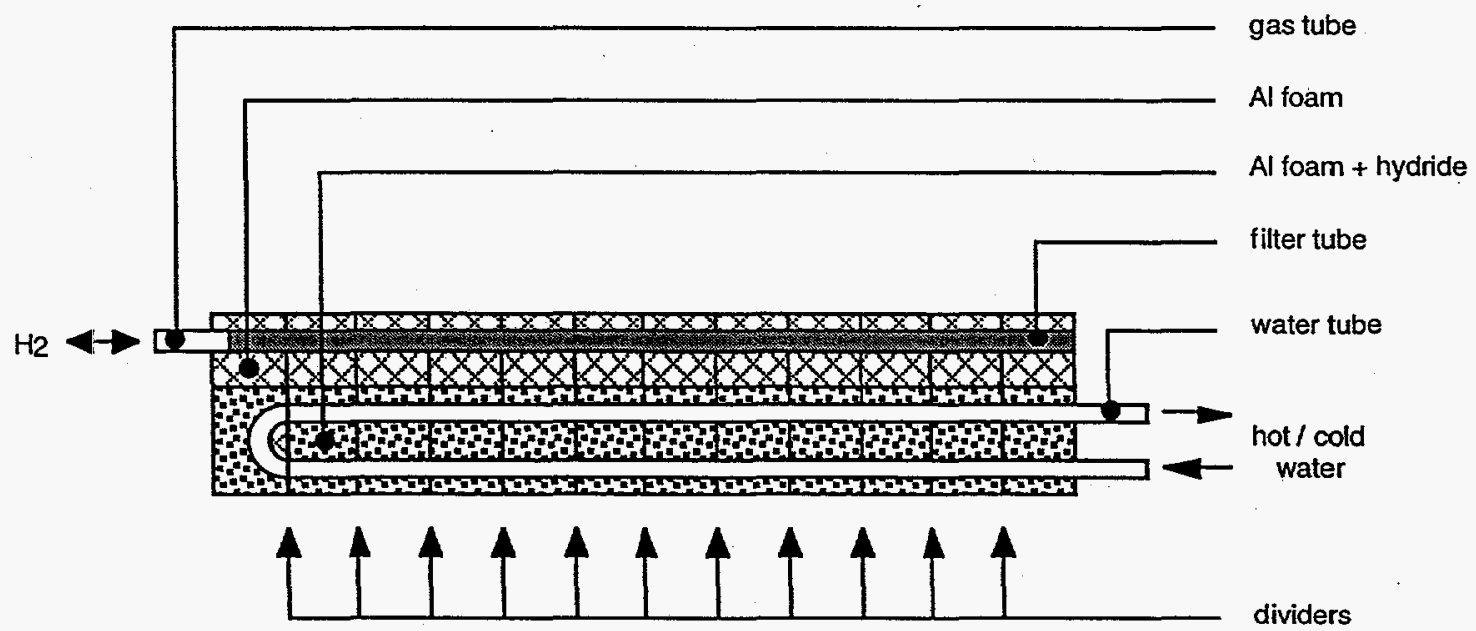

Figure 1. Hydride Bed 


\section{Hydride Materials}

SRTC has over ten years of experience using lanthanum nickel aluminum $\left(\mathrm{LaNi}_{5-\mathrm{x}} \mathrm{Al}_{\mathrm{x}}\right)$ materials in various metal hydride applications. This experience led SRTC to select lanthanum-rich mischmetal nickel aluminum $\left(\mathrm{Lm}_{x} \mathrm{Ni}_{5-x-y} \mathrm{Al}_{y}\right)$ as the preferred type of hydride material for the $\mathrm{H} 2 \mathrm{Fuel}$ bus. Mischmetal (Mm) is a naturally occurring mixture of rare earth elements $(\mathrm{La}, \mathrm{Ce}, \mathrm{Pr}, \mathrm{Nd}, . .$.$) , and is much less expensive than pure lanthanum;$ however, impurities (such as cerium) can cause a significant reduction in hydrogen capacity and an increase in the slope of the isotherm pressure plateau. Thus, lanthanum-rich mischmetal, $\mathrm{Lm}$, was chosen as an economic and performance compromise between pure lanthanum and common mischmetal. The amount of aluminum was then chosen to achieve the required desorption pressure at the expected range of operating temperature. Initial tests of the prototype bed by HCI showed that the desorption pressure needed to be increased by a factor or 2 or 3 to satisfy the pressure requirements of the internal combustion engine. This increase in desorption pressure was achieved by reducing the relative amount of aluminum in the final hydride material. The nominal formula for these two materials is: $\mathrm{Lm}_{1.05} \mathrm{Ni}_{4.95-\mathrm{x}} \mathrm{Al}_{\mathrm{x}}$. where, $\mathrm{x}=0.21$ for the prototype material and $\mathrm{x}=0.03$ for the final material. The formula weights of the prototype and final hydride materials are approximately 430.9 and 437.3 , respectively.

\section{Gas Manifold}

Figure 2 is a schematic diagram of the gas manifold used in these tests. Besides the H2Fuel prototype hydride bed, the main components and features of this manifold include:

- a compressed gas supply with pressure regulator (0-400 psig) and $2 \mu \mathrm{m}$ particle filter

- a vent with backpressure regulator (0-150 psig)

- a vacuum pump (Alcatel 2008A) with a molecular sieve trap on its gas inlet connection

- a mass flow controller (0-100 slpm H2)

- a 50 liter tank for bed volume and gas flow rate calibrations

- two existing hydride beds containing $\mathrm{LaNi}_{4.25} \mathrm{Al}_{0.75}$ material

- ten type-J thermocouples

- seven 0-25000 torr pressure transducers (MKS model 220-25000)

This manifold design enables gas to be directed through the mass flow controller from any of four hydrogen sources (compressed gas cylinder plus three hydride beds) to any of five hydrogen sinks (three hydride beds plus the vent and vacuum lines). All of these absorption tests used a compressed gas cylinder to supply hydrogen to the prototype bed. All of the desorption tests simply vented the hydrogen removed from the prototype bed. 
WSRC-TR-96-0342

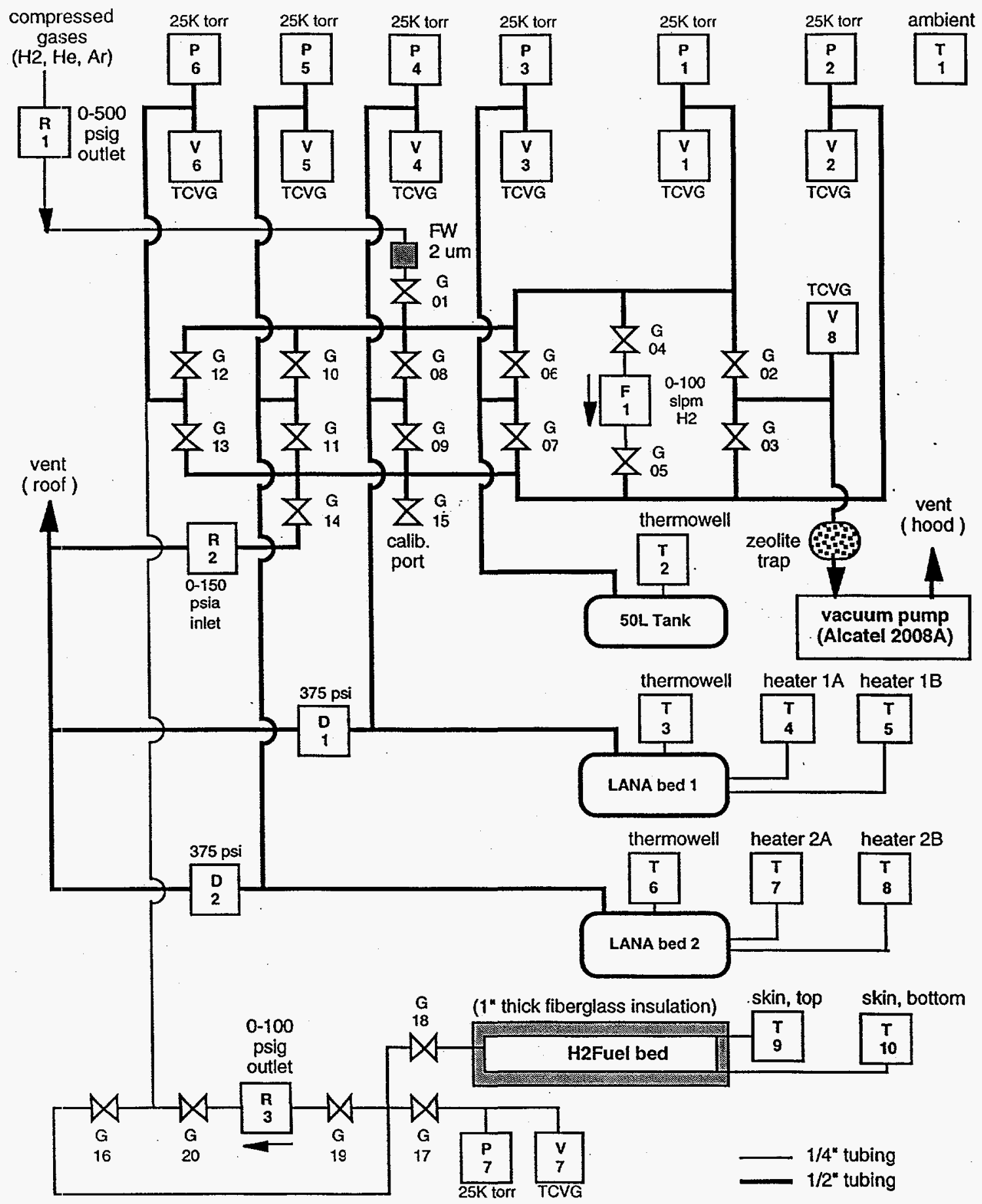

Figure 2. Gas Manifold 


\section{Water Manifold}

The H2Fuel hydride bed is heated and cooled by water which is circulated through an internal U-shaped tube. Cool water (about $25 \mathrm{degC}$ ) is used to absorb hydrogen and warm water ( 40 to $60 \mathrm{degC}$ ) is used to desorb hydrogen. Figure 3 is a schematic diagram of the water manifold. This manifold includes a connection to the building water drain plus three independent water sources (building water plus two water baths). All of the hydrogen absorption tests used building water in a single-pass flow arrangement to cool the bed. All of the hydrogen desorption tests used water recirculated from the hot/cold water bath to heat the bed. Thermocouples were used to measure the temperature of the bed's inlet and outlet water streams as well as the temperature of the outer surface (top and bottom) of the bed vessel. Two rotameters (0.1-1.0 gpm and 0.5-5.0 gpm) installed in series were used to measure the flow rate of water through the bed. Fiberglass pipe insulation (1" thick) was used to reduce heat transfer through the outer wall of the bed.

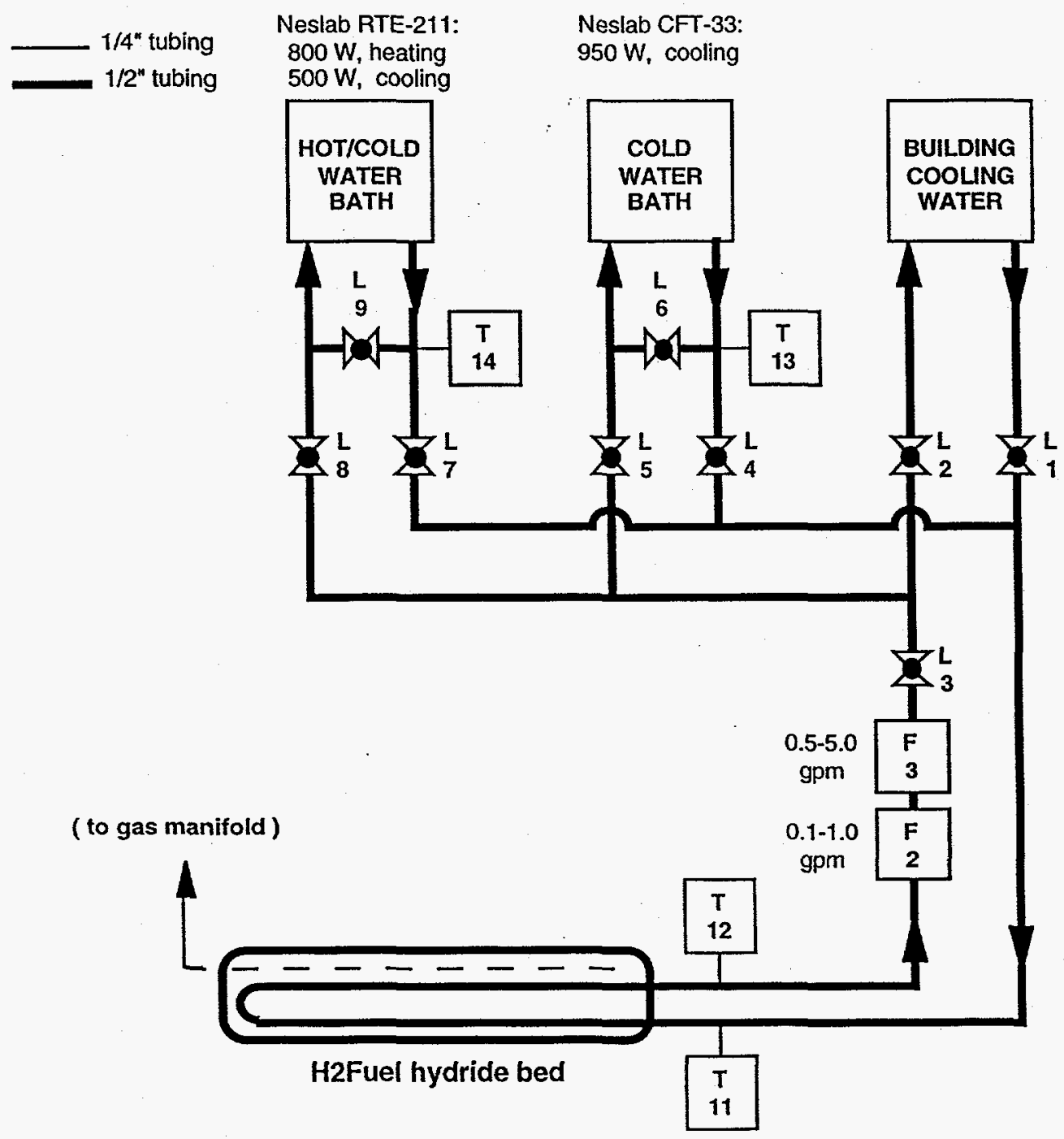

Figure 3. Water Manifold 


\section{Data Acquisition System}

Most of the experimental data was measured and recorded with a computer based data acquisition system (DAS). The DAS hardware consisted of a Macintosh IIx computer connected via a GPIB interface to a Hewlett Packard 3852A data acquisition unit. The DAS software, HBUS, was written using National Instruments' LabVIEW development system (version 2.2.1). The HBUS software enabled the user to monitor and optionally record the following data: timestamp (elapsed seconds), temperature (degC), pressure (psia), vacuum (torr), gas flow rate setpoint and measurement (slpm $\mathrm{H}_{2}$ ), and total gas flow (STP liters $\mathrm{H}_{2}$ ). Prior to the first hydrogen absorption test all of the measurement instrumentation was calibrated to ensure consistency and accuracy of the computer recorded data.

Figure 4 shows the main window of the HBUS software. This window provides an overview of the entire manifold status. The HBUS program included four additional windows which provided separate graphical trend displays for temperature, pressure, vacuum, and gas flow rate data. The HBUS program was generally configured to record new data every ten seconds. During slowly changing conditions the time between data points was increased to 1,2 or 10 minutes.

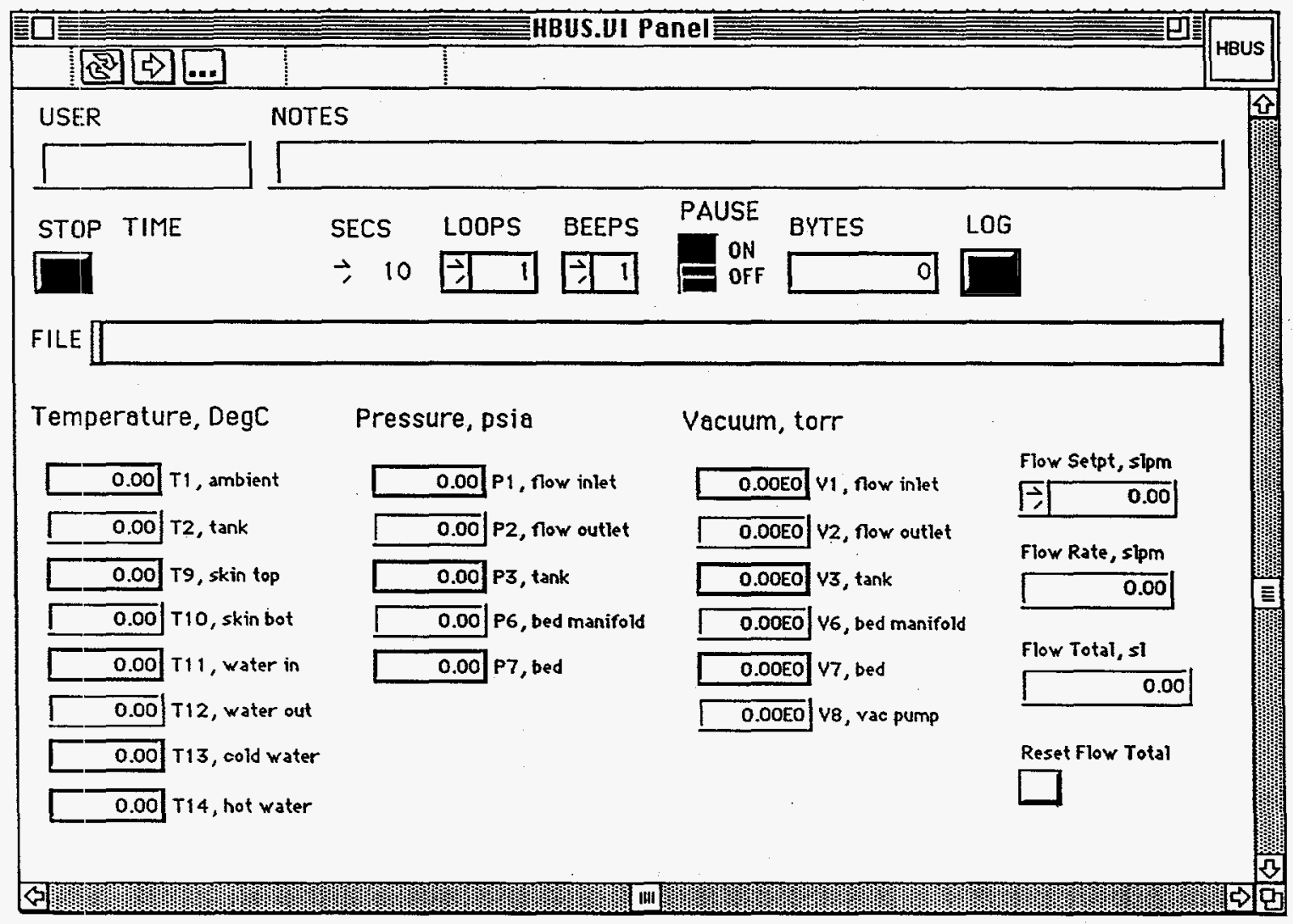

Figure 4. HBUS Software 
WSRC-TR-96-0342

\section{Absorption Tests}

Before it was shipped from HCI to SRTC, the H2Fuel prototype hydride bed was desorbed of residual hydrogen and filled with argon to 30 psia. Prior to hydrogen tests by SRTC this argon was vented/evacuated overnight $(12+$ hours) while the bed was maintained at $60 \mathrm{degC}$. Table 1 lists the conditions for each of the seven absorption tests which included four supply pressures $(75,100,140$, and 300 psia) and two water flow rates $(1.0$ and $5.6 \mathrm{lpm})$. The first five tests used a mass flow controller $\left(100 \mathrm{slpm} \mathrm{H}_{2}\right.$ setpoint) to measure absorbed hydrogen. During the last two absorption tests, ABS-13 and ABS-14, the mass flow controller was bypassed and readings from the inlet gauge of the hydrogen cylinder's pressure regulator to estimate absorbed hydrogen. This technique resulted in an overestimate of absorbed hydrogen in ABS-13 and ABS-14, so data from the corresponding desorption tests (DES-13 and DES-14) were used to correct these results.

Figure 5 shows the results of each absorption test as a plot of absorbed hydrogen (STP liters) versus elapsed time (hours). All of these tests used a cooling water flow rate of 1.0 lpm except for ABS-11 which used a flow rate of $5.6 \mathrm{lpm}$. Comparison of these data show that hydrogen absorption capacity increases with increasing supply pressure and that hydrogen absorption rate increases with increasing supply pressure and/or cooling water circulation rate. Absorption rates for the final hydride beds can be estimated from these prototype data by defining a charge pressure ratio, $\mathrm{P}^{*}$, as:

$$
\text { P* } \equiv \text { (supply pressure) / (equilibrium absorption plateau pressure) }
$$

Figure 6 shows a plot of equilibrium absorption plateau pressure versus inverse temperature for both the prototype and final hydride alloys. From these data the equilibrium absorption plateau pressures of the prototype and final hydrides are estimated to be $2.74 \mathrm{~atm}$ (40.3 psia) and $5.90 \mathrm{~atm}$ ( 86.7 psia), respectively.

Table 2 lists the resulting charge pressure ratios for each of the four prototype bed charge pressures $(70,100,140$, and 300 psia), plus two charge pressures for the final bed (240 and 365 psia). Table 2 shows that the current charge pressure ratio for the final beds $\left(\mathrm{P}^{*}=\right.$ $2.77)$ is comparable to the ABS-09 prototype test $\left(\mathrm{P}^{*}=2.78\right)$, and the proposed charge pressure ratio for the final beds $\left(\mathrm{P}^{*}=4.01\right)$ is slightly higher than the $\mathrm{ABS}-10$ prototype test $\left(\mathrm{P}^{*}=3.89\right)$. Thus, the ABS-09 and ABS-10 curves in Figure 5 can be used to estimate absorption rates for the final hydride beds for the current and proposed charge pressures, respectively. 
WSRC-TR-96-0342

Table 1. Absorption Conditions

\begin{tabular}{|c|c|c|c|c|}
\hline $\begin{array}{c}\text { TEST } \\
\text { NAME }\end{array}$ & $\begin{array}{c}\mathrm{T}, \mathrm{H}_{2} \mathrm{O} \\
\text { supply } \\
(\operatorname{degC})\end{array}$ & $\begin{array}{l}\mathrm{F}, \mathrm{H}_{2} \mathrm{O} \\
\text { supply } \\
(\mathrm{lpm})\end{array}$ & $\begin{array}{l}\mathrm{P}, \mathrm{H}_{2} \\
\text { supply } \\
\text { ( psia ) }\end{array}$ & $\begin{array}{c}\mathrm{F}, \mathrm{H}_{2} \\
\text { setpt } \\
(\mathrm{slpm})\end{array}$ \\
\hline$\overline{\mathrm{ABS}}-08$ & 25 & 1.0 & 75 & 100 \\
\hline ABS-09 & 25 & 1.0 & 100 & 100 \\
\hline ABS-10 & 25 & 1.0 & 140 & 100 \\
\hline ABS-11 & 25 & 5.6 & 75 & 100 \\
\hline ABS-12 & 25 & 1.0 & 75 & 100 \\
\hline ABS-13 & 25 & 1.0 & 300 & none \\
\hline ABS-14 & 25 & 1.0 & 75 & none \\
\hline
\end{tabular}

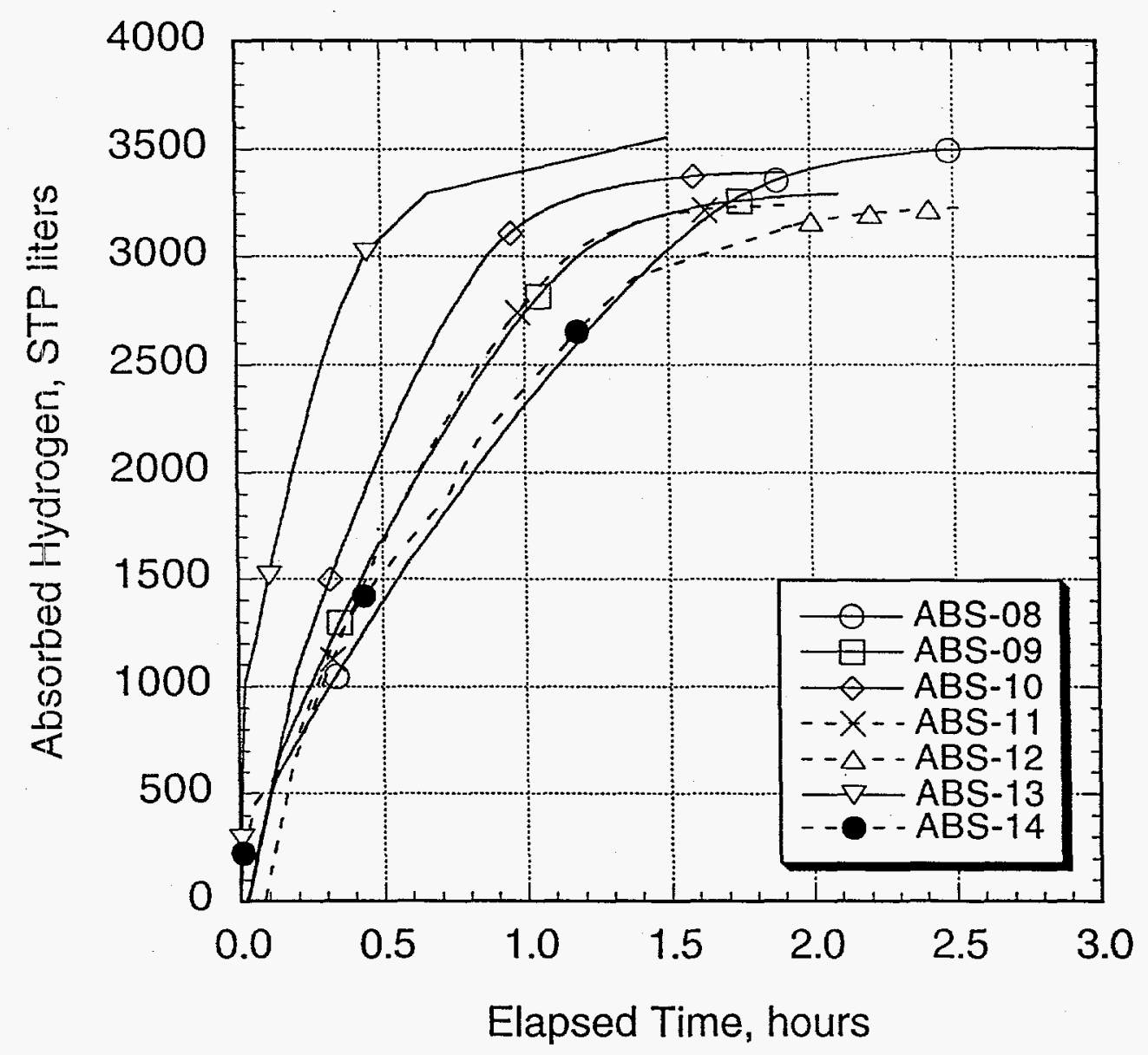

Figure 5. Absorption Results 


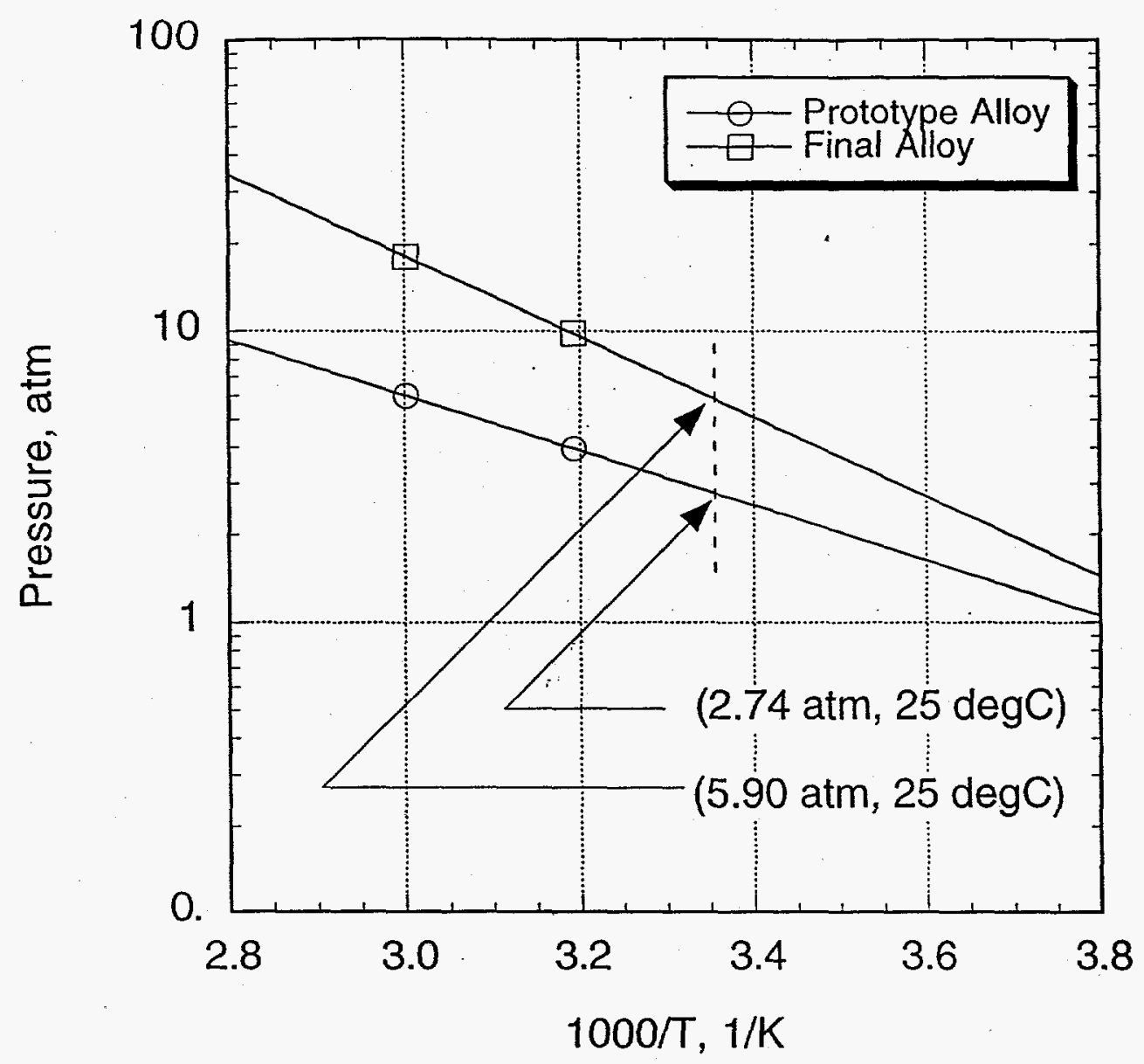

Figure 6. Equilibrium Absorption Plateau Pressures

Table 2. Charge Pressure Ratios

\begin{tabular}{|cccc|}
\hline P, psia & P* & Material & Tests \\
75 & 2.08 & prototype & ABS-08,11,12,14 \\
100 & 2.78 & prototype & ABS-09 \\
140 & 3.89 & prototype & ABS-10 \\
300 & 8.33 & prototype & ABS-14 \\
\hline 240 & 2.77 & final & current \\
365 & 4.01 & final & proposed \\
\hline
\end{tabular}

$\mathrm{P}^{*} \equiv$ (supply pressure) / (equilibrium absorption plateau pressure) 


\section{Desorption Tests}

Table 3 shows the conditions for the seven hydrogen desorption tests of the H2Fuel prototype hydride bed. These tests used three desorption rates (20,30, and $50 \mathrm{slpm})$. The hot water system provided sufficient heat to desorb hydrogen; however, it could not maintain a constant inlet water temperature. During each test the inlet water temperature started at about $60 \mathrm{degC}$, quickly dropped to around $45 \mathrm{degC}$, then slowly increased to approach $60 \operatorname{deg} \mathrm{C}$ as the desorption rate approached zero. Each test was stopped when the hydrogen flow rate dropped below $1.0 \mathrm{slpm}$. The amount of desorbed hydrogen was calculated by numerical integration of mass flow controller readings.

Figure 7 shows the overall results of these tests in a plot of desorbed hydrogen (STP liters) versus elapsed time (hours). The endpoint of each curve provides a good measurement of the bed's maximum desorption capacity. A rough estimate of the useable desorption capacity is the point at which each curve shows a significant decrease in slope.

Analysis of the dynamic desorption pressure of the prototype bed is complex due to variations in the inlet water temperature during each desorption test. For the H2Fuel bus desorption pressure will be controlled by a control system which adjusts the flow of engine coolant through the hydride beds. Excess coolant will be directed through a bypass of the hydride beds. 
WSRC-TR-96-0342

Table 3. Desorption Conditions

\begin{tabular}{|c|c|c|c|}
\hline $\begin{array}{c}\text { TEST } \\
\text { NAME }\end{array}$ & $\begin{array}{l}\mathrm{T}, \mathrm{H}_{2} \mathrm{O} \\
\text { setpoint } \\
(\operatorname{deg} \mathrm{C})\end{array}$ & $\begin{array}{l}\mathrm{F}, \mathrm{H}_{2} \mathrm{O} \\
\text { setpoint } \\
(\mathrm{lpm})\end{array}$ & $\begin{array}{c}\mathrm{F}, \mathrm{H}_{2} \\
\text { setpoint } \\
\text { ( slpm ) }\end{array}$ \\
\hline DES-08 & 60 & 3.0 & 20 \\
\hline DES-09 & 60 & 3.0 & 30 \\
\hline DES-10 & 60 & 5.6 & 20 \\
\hline DES-11 & 60 & 5.6 & 20 \\
\hline DES-12 & 60 & 3.0 & 30 \\
\hline DES-13 & 60 & 3.0 & 30 \\
\hline DES-14 & 60 & 3.0 & 50 \\
\hline
\end{tabular}

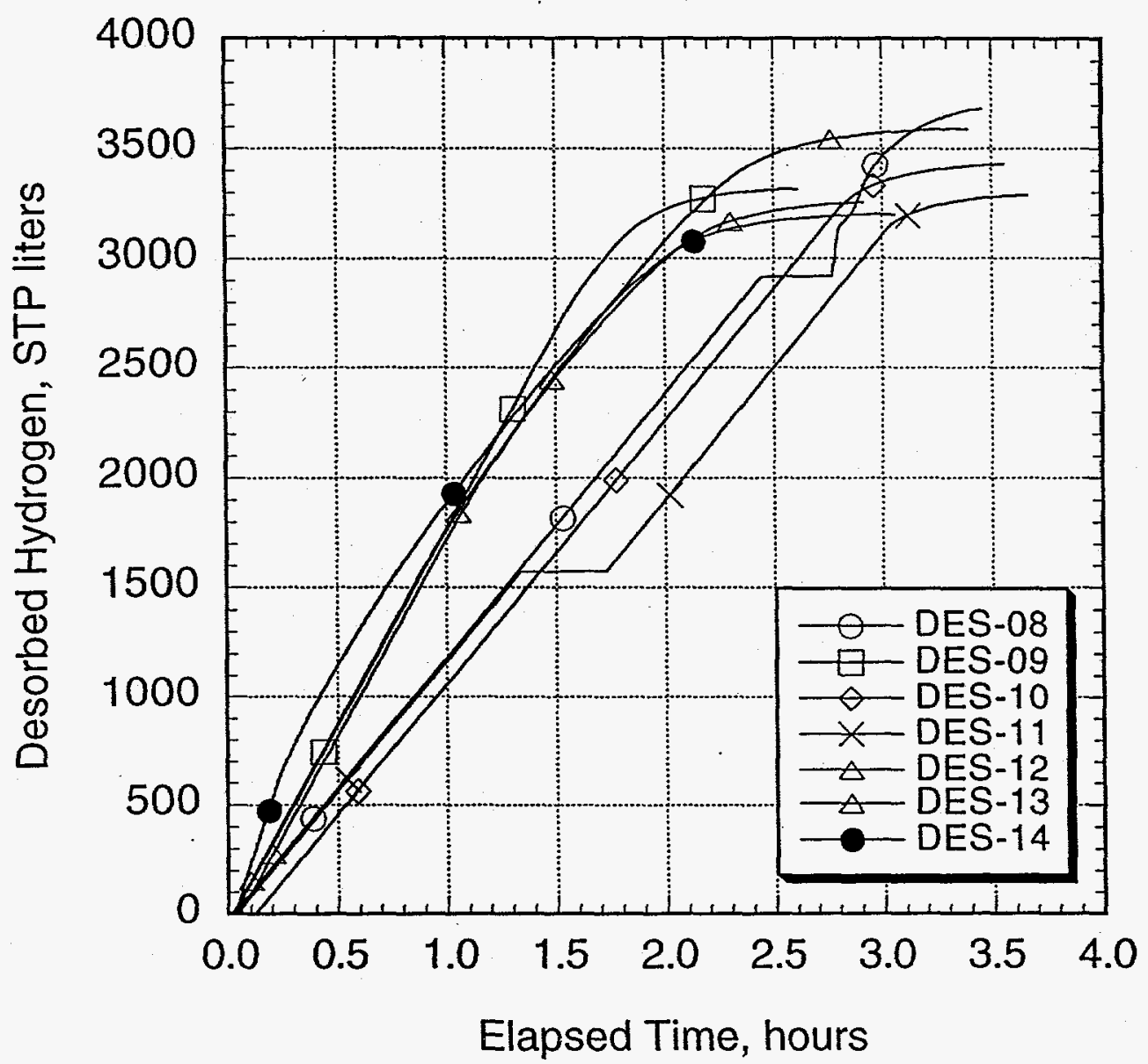

Figure 7. Desorption Results 


\section{Diameter Measurements}

After the last desorption test (DES-14) the bed was heated at $60 \mathrm{degC}$ and evacuated for $12+$ hours to remove residual hydrogen. Then the bed was cooled to $20 \mathrm{degC}$, filled with argon to 30 psia, isolated from the manifold (closed and plugged the bed's gas connection valve), and final diameter measurements were made. The outer diameter of the bed was measured before and after hydrogen testing to check for swelling of the bed. A 6" digital caliper ( 0.001 " resolution) was used to measure the bed diameter in twenty four locations two angles (vertical and horizontal) at the axial midpoint of each of the bed's twelve sections. A constant and consistent bed temperature was maintained during all diameter measurements by circulating water from the hot/cold water bath $(20 \mathrm{degC}, 1.0 \mathrm{lpm})$ though the bed's heating/cooling U-tube. Table 5 shows the results of these diameter measurements. Analysis of these data show no measurable swelling of the hydride bed.

Table 4. Bed Diameters

\begin{tabular}{|c|c|c|c|c|c|c|c|}
\hline Count & Section & Angle & Position, mm & D1, in. & D2, in. & D3, in. & D4, in. \\
\hline 1 & 1 & horizontal & 69 & 3.496 & 3.495 & 3.495 & 3.499 \\
\hline 2 & 1 & vertical & 69 & 3.490 & 3.500 & 3.490 & 3.489 \\
\hline 3 & 2 & horizontal & 195 & 3.506 & 3.507 & 3.510 & 3.511 \\
\hline 4 & 2 & vertical & 195 & 3.487 & 3.488 & 3.490 & 3.487 \\
\hline 5 & 3 & horizontal & 321 & 3.506 & 3.508 & 3.508 & 3.506 \\
\hline 6 & 3 & vertical & 321 & 3.490 & 3.491 & 3.489 & 3.489 \\
\hline 7 & 4 & horizontal & 447 & 3.506 & 3.509 & 3.510 & 3.506 \\
\hline 8 & 4 & vertical & 447 & 3.493 & 3.497 & 3.493 & 3.491 \\
\hline 9 & 5 & horizontal & 573 & 3.501 & 3.509 & 3.505 & 3.500 \\
\hline 10 & 5 & vertical & 573 & 3.495 & 3.505 & 3.498 & 3.499 \\
\hline 11 & 6 & horizontal & 699 & 3.501 & 3.507 & 3.501 & 3.502 \\
\hline 12 & 6 & vertical & 699 & 3.495 & 3.498 & 3.498 & 3.496 \\
\hline 13 & 7 & horizontal & 825 & 3.496 & 3.503 & 3.499 & 3.497 \\
\hline 14 & 7 & vertical & 825 & 3.492 & 3.494 & 3.495 & 3.493 \\
\hline 15 & 8 & horizontal & 951 & 3.502 & 3.504 & 3.507 & 3.506 \\
\hline 16 & 8 & vertical & 951 & 3.497 & 3.501 & 3.495 & 3.495 \\
\hline 17 & 9 & horizontal & 1077 & 3.505 & 3.505 & 3.506 & 3.506 \\
\hline 18 & 9 & vertical & 1077 & 3.496 & 3.498 & 3.492 & 3.492 \\
\hline 19 & 10 & horizontal & 1203 & 3.508 & 3.508 & 3.507 & 3.510 \\
\hline 20 & 10 & vertical & 1203 & 3.497 & 3.496 & 3.496 & 3.496 \\
\hline 21 & 11 & horizontal & 1329 & 3.504 & 3.506 & 3.505 & 3.503 \\
\hline 22 & 11 & vertical & 1329 & 3.500 & 3.503 & 3.504 & 3.494 \\
\hline 23 & 12 & horizontal & 1455 & 3.499 & 3.499 & 3.497 & 3.501 \\
\hline 24 & 12 & vertical & 1455 & 3.497 & 3.498 & 3.500 & 3.504 \\
\hline & & & & & & \\
\hline
\end{tabular}

Position is defined as the distance from the outer edge of the gas connection end plate.

Four sets (D1, D2, D3, D4) of diameter measurements.

Before hydrogen tests $(5 / 17 / 96) \ldots$ D1 \& D3 $=30$ psia Ar, D2 $=300$ psia Ar _ After hydrogen tests $(9 / 19 / 96) \ldots$ D4 $=30$ psia Ar 


\section{CONCLUSIONS}

The H2Fuel prototype hydride bed is 60 " long, 3.5 " in diameter, contains $25.8 \mathrm{~kg}$ of hydride $(\mathrm{FW}=430.9 \mathrm{~g} / \mathrm{mol}$ ), weighs $35.9 \mathrm{~kg}$ (hydride + vessel), and has a maximum working pressure of $500 \mathrm{psig}$. Performance testing of this bed by SRTC included fourteen hydrogen tests (seven absorption-desorption cycles) plus vessel diameter measurements before and after the hydrogen tests. Approximately two to three hours are required to charge the bed to its maximum hydrogen capacity of approximately 3500 STP liters $(0.315$ $\mathrm{kg}$ ). Consideration of charge times and discharge pressure reduces the practical hydrogen capacity to approximately 3000 STP liters $(0.270 \mathrm{~kg})$. Hydrogen desorption was demonstrated at rates up to $50 \mathrm{slpm}$. Diameter measurements before and after hydrogen testing showed no vessel swelling.

\section{SUMMARY}

These tests by SRTC confirm and extend the results of previous tests by HCI. The H2Fuel prototype hydride bed was confirmed to have good hydrogen performance except that its desorption pressure is too low to meet the requirements of the internal combustion engine. The composition of the final hydride material was adjusted to achieve the necessary increase in desorption pressure. Previous results were extended by the use of higher charging pressures and higher discharging rates to bracket the expected operating conditions of the final hydride beds. 